\title{
Rekomendasi Pemilihan Baju Wanita dengan Metode Naive Bayes
}

\author{
Ari Avianto $^{1 *}$, Nur Nafi'iyah ${ }^{1}$, Nur Qomariyah Nawafilah $^{3}$ \\ ${ }^{1,3}$ Program Studi Teknik Informatika, Fakultas Teknik, Universitas Islam Lamongan \\ Jalan Veteran Nomor 53A Lamongan, 62211 \\ e-mail: ariavianto01@gmail.com
}

\begin{abstract}
Abstrak - Algoritma Naïve Bayes dapat digunakan untuk rekomendasi baju wanita. Metode ini akan diterapkan untuk memberikan rekomendasi pemilihan baju wanita sesuai kelas baju karakter konsumen. Tujuan penelitian, yaitu membuat sistem yang dapat digunakan untuk memberikan rekomendasi baju dengan algoritma Naïve Bayes. Kategori baju yang direkomendasikan adalah Blouses, Dresses, Jackets dan Jeans. Jumlah dataset yang digunakan sebanyak 500 data yaitu 490 data training dan 10 data testing yang terbagi kedalam 7 atribut yaitu Age, Rating, Recommended IND, Positive Feedback Count, Division Name, Departement Name dan Class Name, aplikasi penerapan metode naive bayes ini dapat memberikan Sistem Pendukung Keputusan (SPK) Rekomendasi Pemilihan Baju Wanita dengan akurasi $80 \%$.
\end{abstract}

Kata kunci: rekomendasi baju wanita, naive bayes.

\section{Pendahuluan}

Pembelian dan penjualan secara online menjadi suatu perkembangan dalam dunia perdagangan. Karena masyarakat dapat membeli baju atau menjual baju tanpa harus bertatap muka. Dengan banyaknya website atau e-commerce yang menyediakan produk baju ataupun lainnya dalam jual beli. Maka dari transaksi tersebut akan terekap dalam dataset. Kumpulan dataset tersebut dapat digunakan sebagai informasi atau pengetahuan. Transaksi jual beli yang sudah terekap dan tersimpan dalam database dapat diolah. Data mining adalah proses mengolah dan menggali informasi dan pengetahuan dari kumpulan dataset. Proses menggali akan dapat digunakan untuk memberikan rekomendasi pada pembeli baru. Algoritma yang dapat digunakan untuk menggali data, salah satunya algoritma naive bayes. Di mana proses mendapatkan pengetahuan berdasarkan dataset yang dihitung nilai probabilitasnya[1]. Dalam penelitian ratih menyebutkan bahwa pembeli akan kebingungan dengan banyaknya pilihan baju yang ditawarkan dalam e-commerce. Dan pembeli akan lebih dimudahkan jika sistem atau e-commerce memberikan rekomendasi baju yang sesuai tipe tubuh, bahan, model, warna dan harga berdasarkan data transaksi jual beli di e-commerce. Kategori yang dipakai untuk memberikan rekomendasi berdasarkan style, price, rating, size, season, neckline, sleevelength, waiseline, material, febrictype, decoration, patterntype, recommendation[1].

Penelitian lainnya terkait algoritma Naïve Bayes yang digunakan pada website e-commerce adalah Zia Ayu. Di mana algoritma naïve bayes digunakan untuk mengklasifikasi ulasan atau komentara para pembeli di aplikasi Shopee. Proses klasifikasi ulasan atau komentar mengenai pelayanan dan produk, seperti dari hal ongkir, buruk, susah, gambar, pengiriman, dan penjual. Kelas klasifikasi terhadap komentar adalah puas atau tidak puas, atau positif dan negatif[2]. Klasifikasi dapat menggunakan berbagai algoritma, dan algoritma naïve bayes memberikan nilai akurasi yang tinggi. Pada penelitian Zia Ayu, proses klasifikasi komentar pembeli pada aplikasi Shopee akurasinya 97,4\%[2]. Pada penelitian Nur Nafi'iyah, dan Mochammad Ainun dengan menggunakan algoritma Naïve Bayes secara berturut-turut nilai akurasinya $80 \%$ [5], dan $74,5 \%[6]$.

Dari beberapa penelitian sebelumnya maka peneliti ingin mengimplementasikan algoritma naïve bayes dalam memberikan rekomendasi baju wanita berdasarkan kriteria age, rating, recommended, positive feedback count, devision name, departement name. Dan kelas rekomendasi Blouses, Dresses, Jackets, dan Jeans.

\section{Tinjauan Pustaka}

\subsection{Naive Bayes}

Naive bayes suatu algoritma yang menerapkan nilai probabilitas dari suatu kemungkinan antara data query terhadap dataset. Di mana data query akan dihitung nilai probabilitasnnya berdasarkan dataset. Proses menghitung nilai probabilitas dengan Persamaan 1.

$$
p(H \mid E)=\frac{p(E \mid H)^{*} p(H)}{p(E)}
$$

Di mana $\mathrm{p}(\mathrm{H} \mid \mathrm{E})$ adalah nilai probabilitas hipotesis terhadap evidance/variabel. Dan $p(E \mid H)$ adalah nilai probabilitas evidance query terhadap semua kelas hipotesis. Dan $\mathrm{p}(\mathrm{H})$ adalah nilai 
probabilitas semua kelas terhadap semua dataset. $\mathrm{P}(\mathrm{E})$ adalah nilai probabilitas evidance (semua variabel input). Dan untuk menghitung probabilitas hipotesis dalam Persamaan 2.

$$
p(H)=\frac{N_{\text {kelas }}}{N_{\text {seluruh_dataset }}}
$$

Algoritma dari data mining yang juga dapat digunakan dalam jual beli online atau e-commerce adalah association Rule. Di mana algoritma association rule yang digunakan dalam penelitian Arif Ismail dan kawan-kawan adalah Apriori. Algoritma Apriori digunakan untuk strategi menyusun etalase penjualan pakaian. Etalase berjualan secara online perlu disusun secara strategis agar dapat meningkatkan penjualan[3]. Hasil dari penelitian Arif Ismail mengatakan bahwa adanya hubungan antara baju yang dibeli bersamaan terhadap penyusunan etalase[3]. Market Analisis juga salah satu algoritma data mining association rule, di mana market basket analisis dapat digunakan untuk menyusun tata letak jualan pada Minimarket Aira. Salah satu contoh penyusunan tata letak jualannya, yaitu antara menyusun snack kacang dengan minuman kopi. Ditunjukkan dari hasil market basket analisis konsumen yang membeli snack kacang maka 97,2\% akan membeli snack lainnya, dan $95 \%$ akan membeli kopi[4].

\section{Metode Penelitian}

Sistem rekomendasi pemilihan baju wanita menggunakan metode Nä̈ve bayes mempunyai beberapa tahapan. Langkah pertama yang dilakukan dalam metode Nä̈ve bayes yaitu menghitung nilai probabilitas $\mathrm{P}(\mathrm{H})$ dengan cara menghitung jumlah item berdasarkan class name kemudian dibagi dengan jumlah dataset keseluruhan seperti dalam Persamaan 2.Langkah kedua menghitung data item query yang diinputkan dibagi dengan nilai jumlah tiap kelas tersebut $\mathrm{P}(\mathrm{E} \mid \mathrm{H})$.Kemudian mengkalikan nilai $\mathrm{P}(\mathrm{E} \mid \mathrm{H})$ berdasarkan classname nya masing-masing, langkah terakhir yaitu mengkalikan hasil nilai $\mathrm{P}(\mathrm{E} \mid \mathrm{H})$ dengan nilai probabilitas setiap kelas $\mathrm{P}(\mathrm{H})$.Sehingga akan didapatkan hasil dari item rekomendasi untuk konsumen masuk kedalam class name yang nilai probabilitas tertinggi. Dalam proses perhitungan naive baiyes dibutuhkan data training,dalam kasus ini penulis menggunakan data pemilihan baju wanita sebagai data training dalam Tabel 1.

Berdasarkan Tabel 1 dapat dihitung klasifikasi data baju wanita apabila diinputkan Data testing: $\mathrm{X}=$ (Age $=54$, Rating $=5$, Recommended IND $=1$, Positif feedback count $=0$, Division name $=$ General,
Departement name $=$ Dresses, Class name $=$ Dresses $)$ menggunakan metode Naive Bayes, maka klasifikasi data baju wanita dapat ditentukan melalui langkah berikut:

$\mathbf{P}(\mathbf{C i})$

$\mathrm{P}($ Class name $=$ "Dresses" $)=42 / 114=$ 0,3684210526

$\mathrm{P}($ Class name $=$ "Blouses" $)=61 / 114=$ 0,5350877193

$\mathrm{P}($ Class name $=$ "Jackets" $)=5 / 114=0,0438596491$

$\mathrm{P}($ Class name $=$ "Jeans" $)=6 / 114=0,0526315789$

\section{$\mathbf{P}(\mathbf{X} \mid \mathbf{C i})$}

$\mathrm{P}($ Age = "54" $\mid$ Class name $=$ "Dresses" $)=1 / 42=$ 0,0238095238

$\mathrm{P}($ Age $=$ "54" $\mid$ Class name $=$ "Blouses" $)=1 / 61=$ 0,0163934426

$\mathrm{P}($ Age $=$ "54" $\mid$ Class name $=$ "Jackets" $)=0 / 5=0$

$\mathrm{P}($ Age $=$ "54" $\mid$ Class name $=$ "Jeans" $)=0 / 6=0$

$\mathrm{P}($ Rating = "5" $\mid$ Class name $=$ "Dresses" $)=19 / 42=$ 0,4523809524

$\mathrm{P}($ Rating = "5" $\mid$ Class name = "Blouses" $)=28 / 61$

$=0,4590163934$

$\mathrm{P}($ Rating = "5" $\mid$ Class name $=$ "Jackets" $)=3 / 5=0,6$

$\mathrm{P}($ Rating $=$ "5" $\mid$ Class name $=$ "Jeans" $)=4 / 6=$

0,6666666667

$\mathrm{P}($ Recommended IND = " 1 " | Class name = "Dresses") $=35 / 42=0,8333333333$

$\mathrm{P}($ Recommended IND = " 1 " $\mid$ Class name $=$

"Blouses") $=47 / 61=0,7704918033$

$\mathrm{P}($ Recommended IND = " 1 " $\mid$ Class name =

"Jackets") $=5 / 5=1$

$\mathrm{P}($ Recommended IND = " 1 " $\mid$ Class name $=$ "Jeans") $=6 / 6=1$

$\mathrm{P}($ Positif feedback count $=$ " 0 " $\mid$ Class name $=$ "Dresses") = 20/42 =0,4761904762

$\mathrm{P}($ Positif feedback count $=$ "0" $\mid$ Class name $=$ "Blouses") = 23/61 =0,3770491803

$\mathrm{P}($ Positif feedback count $=$ " 0 " $\mid$ Class name $=$ "Jackets") $=4 / 5=0,8$

$\mathrm{P}($ Positif feedback count $=$ " 0 " $\mid$ Class name $=$ "Jeans") $=2 / 6=0,3333333333$

$\mathrm{P}$ (Division name $=$ "General" $\mid$ Class name $=$ "Dresses") = 27/42 =0,6428571429

$\mathrm{P}($ Division name $=$ "General" $\mid$ Class name $=$ "Blouses") = 43/61 = 0,7049180328

$\mathrm{P}($ Division name $=$ "Generale" $\mid$ Class name $=$ "Jackets") $=4 / 5=0,8$

$\mathrm{P}($ Division name $=$ "General" $\mid$ Class name $=$ "Jeans") $=6 / 6=1$

$\mathrm{P}($ Departement name $=$ "Dresses" $\mid$ Class name $=$ 
"Dresses") $=42 / 42=1$

$\mathrm{P}($ Departement name $=$ "Dresses" $\mid$ Class name $=$ "Blouses") $=0 / 61=0$

$\mathrm{P}($ Departement name $=$ "Dresses" $\mid$ Class name $=$

"Jackets") $=0 / 5=0$

$\mathrm{P}($ Departement name $=$ "Dresses" $\mid$ Class name $=$ "Jeans") $=0 / 6=0$

$\mathrm{P}(\mathrm{X} \mid$ Class name $=$ "Dresses" $)=0,0238095238 *$ $0,4523809524 * 0,8333333333 * 0,4761904762 *$ $0,6428571429 * 1=0,0027476976$

$\mathrm{P}(\mathrm{X} \mid$ Class name $=$ "Blouses" $)=0,0163934426$ * $0,4590163934 * 0,7704918033 * 0,3770491803 *$ $0,7049180328 * 0=0$

$\mathrm{P}(\mathrm{X} \mid$ Class name $=$ "Jackets" $)=0 * 0,6 * 1 * 0,8 *$ $0,8 * 0=0$

$\mathrm{P}(\mathrm{X} \mid$ Class name $=$ "Jeans" $)=0 * 0,6666666667 * 1$

$* 0,3333333333 * 1 * 0=0$

$\mathbf{P}(\mathbf{X} \mid \mathbf{C i}) * \mathbf{P}(\mathbf{C i})$

$\mathrm{P}($ Class name $=$ "Dresses" $) * \mathrm{P}($ Class name $=$

"Dresses")

$0,0027476976 * 0,3684210526=0,0010122807$

$\mathrm{P}($ Class name $=$ "Blouses" $) * \mathrm{P}($ Class name $=$

"Blouses")

$0 * 0,5350877193=0$

$\mathrm{P}($ Class name $=$ "Jackets" $) * \mathrm{P}($ Class name $=$

"Jackets")

$0 * 0,0438596491=0$

$\mathrm{P}($ Class name $=$ "Jeans" $) * \mathrm{P}($ Class name $=$ "Jeans" $)$ $0 * 0,0526315789=0$

Jadi, untuk Age $=54$, Rating $=5$, Recommended IND $=1$, Positif feedback count $=0$, Division name $=$ General, Departement name $=$ Dresses, Class name = Dresses masukke Class name "Dresses". E-ISSN

\begin{tabular}{|c|c|c|c|c|c|c|c|}
\hline 10 & 50 & 3 & 1 & 1 & General & Dresses & Dresses \\
\hline 11 & 41 & 5 & 1 & 0 & General & Tops & Blouses \\
\hline 12 & 47 & 5 & 1 & 0 & General & Dresses & Dresses \\
\hline 13 & 33 & 4 & 1 & 2 & General & Tops & Blouses \\
\hline 14 & 55 & 4 & 1 & 14 & General & Dresses & Dresses \\
\hline 15 & 31 & 2 & 0 & 7 & General & Dresses & Dresses \\
\hline 16 & 34 & 3 & 1 & 0 & General & Dresses & Dresses \\
\hline 17 & 55 & 5 & 1 & 0 & General & Tops & Blouses \\
\hline 18 & 52 & 5 & 1 & 0 & General & Tops & Blouses \\
\hline 19 & 39 & 3 & 1 & 3 & General & Dresses & Dresses \\
\hline 20 & 36 & 4 & 1 & 0 & General Petite & Dresses & Dresses \\
\hline 21 & 41 & 5 & 1 & 0 & General Petite & Dresses & Dresses \\
\hline 22 & 56 & 3 & 0 & 1 & General Petite & Dresses & Dresses \\
\hline 23 & 38 & 4 & 1 & 10 & General Petite & Tops & Blouses \\
\hline 24 & 36 & 2 & 0 & 0 & General & Tops & Blouses \\
\hline 25 & 27 & 5 & 1 & 4 & General & Tops & Blouses \\
\hline 26 & 59 & 5 & 1 & 1 & General Petite & Dresses & Dresses \\
\hline 27 & 48 & 5 & 1 & 5 & General Petite & Tops & Blouses \\
\hline 28 & 31 & 4 & 1 & 0 & General & Dresses & Dresses \\
\hline 29 & 28 & 2 & 0 & 0 & General Petite & Tops & Blouses \\
\hline 30 & 47 & 5 & 1 & 1 & General & Tops & Blouses \\
\hline 31 & 62 & 4 & 1 & 2 & General Petite & Dresses & Dresses \\
\hline 32 & 68 & 5 & 1 & 1 & General & Dresses & Dresses \\
\hline 33 & 68 & 5 & 1 & 3 & General & Tops & Blouses \\
\hline 34 & 39 & 4 & 1 & 0 & General Petite & Tops & Blouses \\
\hline 35 & 39 & 4 & 1 & 9 & General Petite & Dresses & Dresses \\
\hline 36 & 38 & 2 & 0 & 4 & General Petite & Tops & Blouses \\
\hline 37 & 24 & 4 & 1 & 3 & General & Tops & Blouses \\
\hline 38 & 51 & 4 & 1 & 0 & General Petite & Dresses & Dresses \\
\hline 39 & 29 & 5 & 1 & 5 & General Petite & Tops & Blouses \\
\hline 40 & 31 & 5 & 1 & 0 & General & Dresses & Dresses \\
\hline 41 & 23 & 4 & 1 & 3 & General Petite & Tops & Blouses \\
\hline 42 & 44 & 1 & 0 & 0 & General Petite & Tops & Blouses \\
\hline 43 & 69 & 5 & 1 & 2 & General & Tops & Blouses \\
\hline 44 & 23 & 2 & 0 & 9 & General & Tops & Blouses \\
\hline 45 & 66 & 5 & 1 & 0 & General & Tops & Blouses \\
\hline 46 & 47 & 4 & 1 & 11 & General & Tops & Blouses \\
\hline 47 & 66 & 4 & 1 & 0 & General & Tops & Blouses \\
\hline 48 & 23 & 5 & 1 & 3 & General & Tops & Blouses \\
\hline 49 & 47 & 5 & 1 & 0 & General & Dresses & Dresses \\
\hline 50 & 44 & 3 & 1 & 4 & General & Dresses & Dresses \\
\hline 51 & 50 & 5 & 1 & 24 & General & Tops & Blouses \\
\hline 52 & 61 & 5 & 1 & 3 & General & Dresses & Dresses \\
\hline 53 & 32 & 2 & 0 & 0 & General & Dresses & Dresses \\
\hline 54 & 51 & 4 & 1 & 1 & General & Dresses & Dresses \\
\hline
\end{tabular}

\begin{tabular}{|c|c|c|c|c|c|c|c|c|c|c|c|c|c|c|c|}
\hline \multirow{5}{*}{ ż } & \multirow{5}{*}{$\stackrel{8}{<}$} & \multirow{5}{*}{ 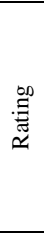 } & \multirow{5}{*}{ 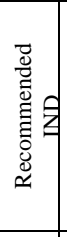 } & \multirow{5}{*}{ 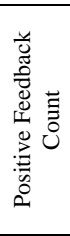 } & \multirow{5}{*}{ 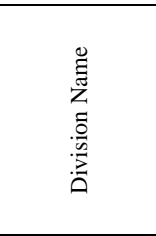 } & \multirow{5}{*}{ 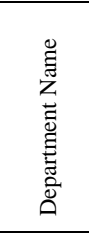 } & \multirow{5}{*}{ 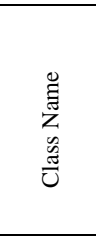 } & 41 & 23 & 4 & 1 & 3 & General Petite & Tops & Blouses \\
\hline & & & & & & & & 42 & 44 & 1 & 0 & 0 & General Petite & Tops & Blouses \\
\hline & & & & & & & & 43 & 69 & 5 & 1 & 2 & General & Tops & Blouses \\
\hline & & & & & & & & 44 & 23 & 2 & 0 & 9 & General & Tops & Blouses \\
\hline & & & & & & & & 45 & 66 & 5 & 1 & 0 & General & Tops & Blouses \\
\hline 1 & 34 & 5 & 1 & 4 & General & Dresses & Dresses & 46 & 47 & 4 & 1 & 11 & General & Tops & Blouses \\
\hline 2 & 60 & 3 & 0 & 0 & General & Dresses & Dresses & 47 & 66 & 4 & 1 & 0 & General & Tops & Blouses \\
\hline 3 & 47 & 5 & 1 & 6 & General & Tops & Blouses & 48 & 23 & 5 & 1 & 3 & General & Tops & Blouses \\
\hline 4 & 49 & 2 & 0 & 4 & General & Dresses & Dresses & 49 & 47 & 5 & 1 & 0 & General & Dresses & Dresses \\
\hline 5 & 24 & 5 & 1 & 0 & General & Dresses & Dresses & 50 & 44 & 3 & 1 & 4 & General & Dresses & Dresses \\
\hline 6 & 34 & 5 & 1 & 0 & General & Dresses & Dresses & 51 & 50 & 5 & 1 & 24 & General & Tops & Blouses \\
\hline 7 & 53 & 3 & 0 & 14 & General & Dresses & Dresses & 52 & 61 & 5 & 1 & 3 & General & Dresses & Dresses \\
\hline 8 & 39 & 5 & 1 & 2 & General Petite & Dresses & Dresses & 53 & 32 & 2 & 0 & 0 & General & Dresses & Dresses \\
\hline 9 & 53 & 5 & 1 & 2 & General Petite & Dresses & Dresses & 54 & 51 & 4 & 1 & 1 & General & Dresses & Dresses \\
\hline
\end{tabular}




\begin{tabular}{|c|c|c|c|c|c|c|c|}
\hline 55 & 32 & 5 & 1 & 2 & General Petite & Dresses & Dresses \\
\hline 56 & 37 & 2 & 0 & 0 & General & Tops & Blouses \\
\hline 57 & 54 & 5 & 1 & 4 & General & Tops & Blouses \\
\hline 58 & 63 & 5 & 1 & 0 & General & Jackets & Jackets \\
\hline 59 & 29 & 5 & 1 & 0 & General Petite & Dresses & Dresses \\
\hline 60 & 24 & 5 & 1 & 0 & General & Tops & Blouses \\
\hline 61 & 34 & 3 & 1 & 1 & General & Dresses & Dresses \\
\hline 62 & 52 & 4 & 1 & 0 & General & Jackets & Jackets \\
\hline 63 & 62 & 4 & 1 & 3 & General Petite & Tops & Blouses \\
\hline 64 & 39 & 3 & 1 & 0 & General & Dresses & Dresses \\
\hline 65 & 36 & 5 & 1 & 0 & General & Jackets & Jackets \\
\hline 66 & 65 & 5 & 1 & 12 & General Petite & Tops & Blouses \\
\hline 67 & 31 & 4 & 1 & 0 & General & Jackets & Jackets \\
\hline 68 & 52 & 4 & 1 & 0 & General & Tops & Blouses \\
\hline 69 & 36 & 5 & 1 & 0 & General & Tops & Blouses \\
\hline 70 & 39 & 4 & 1 & 2 & General & Tops & Blouses \\
\hline 71 & 39 & 3 & 0 & 9 & General & Tops & Blouses \\
\hline 72 & 39 & 3 & 1 & 2 & General & Tops & Blouses \\
\hline 73 & 53 & 3 & 0 & 0 & General & Tops & Blouse \\
\hline 74 & 36 & 3 & 1 & 1 & General & Tops & Blouses \\
\hline 75 & 44 & 3 & 1 & 0 & General Petite & Tops & Blouses \\
\hline 76 & 48 & 5 & 1 & 0 & General Petite & Tops & Blouses \\
\hline 77 & 53 & 4 & 1 & 7 & General Petite & Tops & Blouses \\
\hline 78 & 33 & 4 & 1 & 0 & General Petite & Tops & Blouses \\
\hline 79 & 52 & 1 & 0 & 8 & General Petite & Tops & Blouses \\
\hline 80 & 64 & 4 & 1 & 2 & General Petite & Tops & Blouses \\
\hline 114 & 25 & 5 & 1 & 6 & General & Dresses & Dresses \\
\hline
\end{tabular}

Tabel 1. Data Training

Alur sistem yang akan dibangun seperti dalam Gambar 1. Dan alur dari sistem untuk pengguna dalam Gambar 2.

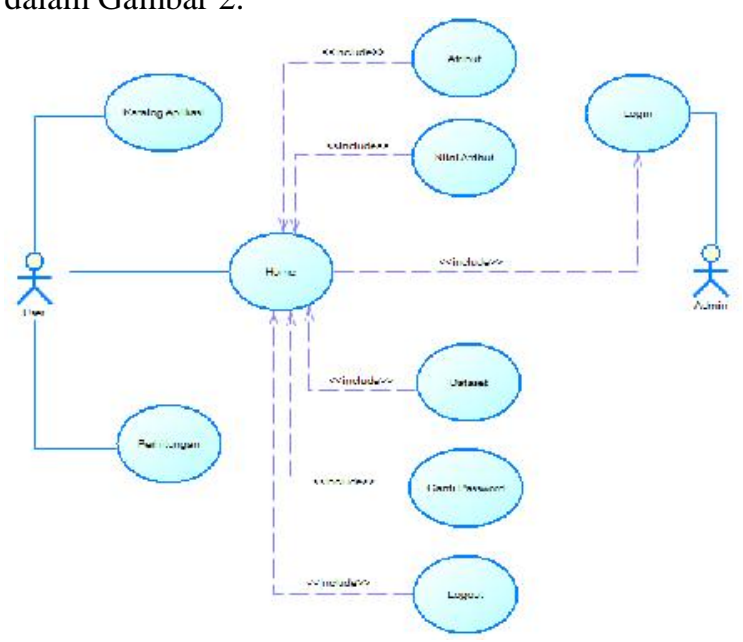

Gambar 1. Usecase Diagram

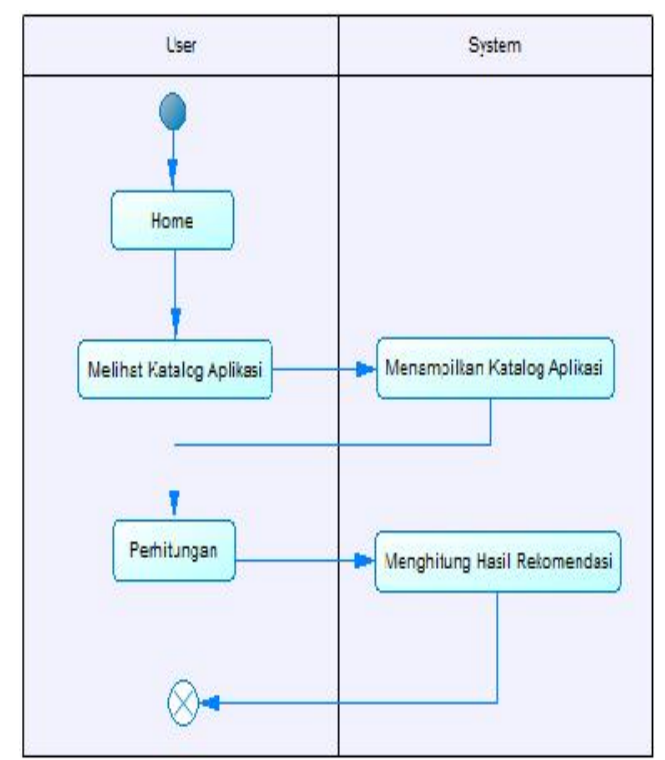

Gambar 2. Alur Kegiatan Pengguna Sistem

\section{Hasil dan Pembahasan}

Sistem ini dibangun menggunakan bahasa PHP dan berbasis web offline. Di mana terdapat beberapa tabel yang berelasi. Diantaranya ada Tabel data training, dan ada Tabel data testing. Tabel data training berisikan dataset yang digunakan sebagai acuan menghitung nilai probabilitas. Dan Tabel data testing sebagai tempat menyimpan data ujicoba dan sekaligus sebagai proses perhitungan nilai akurasi. Sistem ini mempunyai 4 kelas dapat memberikan rekomendasi ke pembeli, yaitu dalam tabel 2. Dan atribut atau variabel yang digunakan, yaitu dalam tabel 3. 


\begin{tabular}{|c|c|}
\hline No & Nilai Atribut \\
\hline 1 & Blouses \\
\hline 2 & Dresses \\
\hline 3 & Jackets \\
\hline 4 & Jeans \\
\hline
\end{tabular}

Tabel 2. Kelas Sistem Rekomendasi Baju Wanita

\begin{tabular}{|c|c|}
\hline No & Atribut \\
\hline 1 & Age \\
\hline 2 & Rating \\
\hline 3 & Recommended IND \\
\hline 4 & Positive Feedback \\
\hline 5 & Devision Name \\
\hline 6 & Departement Name \\
\hline
\end{tabular}

Tabel 3. Atribut atau Variabel Input

Di mana setiap value dari inputan variabel dalam karakter atau number. Misalnya inputan Age dalam number, inputan rating dalam angka akan tetapi mempunyai interval [ $\left.\begin{array}{ll}1 & 5\end{array}\right]$. Variabel yrecommended IND juga berupa number dan mempunyai interval pilihan 0 dan 1 . Variabel positive feedback juga berupa number yang berkisar antara 1100. Sedangkan variabel devision name dan departement name berupa karakter dan kategori. Misalnya devision name kategorinya dalam Tabel 4, dan departement name mempunyai kategori dalam Tabel 5.

\begin{tabular}{|c|c|}
\hline No & Value Kategori \\
\hline 1 & General \\
\hline 2 & General Petite \\
\hline
\end{tabular}

Tabel 4. Nilai Kategori dari Varibel Devision Name

\begin{tabular}{|l|l|}
\hline No & \multicolumn{1}{|c|}{ Value Kategori } \\
\hline 1 & Dresses \\
\hline 2 & Tops \\
\hline 3 & Jackets \\
\hline 4 & Bottoms \\
\hline
\end{tabular}

Tabel 5. Nilai Kategori dari Variabel Departement Name

\section{Kesimpulan}

Sistem ini dibangun menggunakan metode naive bayes sehingga dapat membantu menyelesaikan permasalahan pemilik toko saatmerekomendasikan baju wanita kepada pembeli. Sistem ini disajikan dengan pengklasifikasian baju wanita dengan metode nä̈ve bayes, sehingga mampu memberi rekomendasi pada pemilik toko berdasarkan class "Dresses", "Blouses", “Jackets" dan "Jeans".Hasil dari perhitungan program berdasarkan data testing akurasinya adalah $80 \%$.

\section{Daftar Pustaka}

[1] R. Y. Hayuningtyas, "Penerapan Algoritma Naive Bayes untuk Rekomendasi Pakaian Wanita," Jurnal Informatika, vol. 6, no. 1, pp. 18-22, 2019.

[2] Z. A. N. Gumilang, "Implementasi Naive Bayes Classifier dan Asosiasi untuk Analisis Sentimen Data Ulasan Aplikasi E-Commerce Shopee pada Situs Google Play," Skripsi-Fakultas Matematika dan Ilmu Pengetahuan Alam, Universitas Islam Indonesia Yogyakarta, 2018.

[3] Arif Ismail Husin, Farida Mulyaningsih, "Penerapan Metode Data Mining Analisis Terhadap Data Penjualan Pakaian dengan Algoritma Apriori," in SNIPTEK STMIK Nusa Mandiri, Jakarta, 2015.

[4] J. R. Putri, "Perancangan Ulang Tata Letak Berdasarkan Market Basket Analisis," SkripsiSekolah Tinggi Ilmu Ekonomi, Bandung, 2015.

[5] Nur Nafi'iyah, Siti Mujilahwati, "Analisis Algoritma Backpropagation dan Naive Bayes," in SENASIF, Malang, 2018.

[6] Mochammad Ainun Rozaq, Nur Nafi'iyah, Masruroh, "Sistem Pendukung Keputusan Pemilihan Kualitas Songkok Berdasarkan Bahan Baku Menggunakan Metode Naive Bayes," JMAI, vol. 3, no. 2, pp. 68-72, 2019. 